\title{
LEFT VENTRICULAR ANEURYSM REPAIR IN RATS: STRUCTURAL, FUNCTIONAL, AND MOLECULAR CONSEQUENCES
}

Genichi Sakaguchi, MD

Richard L. Young, $\mathrm{PhD}^{\mathrm{a}}$

Masashi Komeda, MD, $\mathrm{PhD}^{\mathrm{b}^{*}}$

Kazou Yamanaka, MD ${ }^{\mathrm{b}}$

Brian F. Buxton, MB, MS, FRACS ${ }^{b}$

William J. Louis, MD, FRACPa
Objectives: This study examined the effects of aneurysm repair in a rat model of myocardial infarction on functional indices and on the spatiotemporal distribution of cardiac contractile protein and natriuretic peptide messenger RNA.

Methods: In a rat infarct model, expanded left ventricular aneurysms were plicated 4 weeks after infarction. At 30 weeks, transverse heart sections were taken at 4 levels (apex [level 1] through base [level 4]) and assessed by in situ hybridization histochemistry to determine regional messenger RNA levels of pre-pro-atrial natriuretic peptide, cardiac $\alpha$-actin, skeletal $\alpha$-actin, myosin light chain- $2 \mathrm{v}$, and $\beta$-myosin heavy chain.

Results: Rats with plicated left ventricular aneurysms had reduced left ventricular endocardial circumference $(19 \%, P<.005)$, lower heart weight ratio $(31 \%, P<.05)$, left ventricular end-diastolic pressures $(51 \%, P<.05)$, and increased $\pm \mathrm{dP} / \mathrm{dt}(34 \%-38 \%, P<.05)$. Cardiac messenger RNA levels of pre-pro-atrial natriuretic peptide were reduced in the septum (levels 2 and 3), and skeletal $\alpha$-actin levels were reduced in the septum and left ventricular free wall of plicated rats (level 3). $\beta$-Myosin heavy chain levels were markedly reduced in peri-infarct regions of the left ventricular free wall, septum, and right ventricle in plicated rats at level 4 , whereas myosin light chain-2v levels were reduced at levels 2 and 4 in the left ventricular free wall and at level 4 in the right ventricle.

Conclusions: Plication of left ventricular aneurysm after infarction in the rat significantly reduced cardiac hypertrophy, improved cardiac function, and reduced the upregulation of pre-pro-atrial natriuretic peptide and both fetal and adult contractile protein isoforms associated with cardiac hypertrophy.

(J Thorac Cardiovasc Surg 2001;121:750-61)
T: ransmural myocardial infarction (MI) may result in the formation of a large akinetic or dyskinetic infarct scar with progressive remodeling of the ventri-

From the Departments of Clinical Pharmacology and Therapeutics ${ }^{\mathrm{a}}$ and Cardiac Surgery, ${ }^{\mathrm{b}}$ Austin and Repatriation Medical Centre, Heidelberg, Victoria, Australia.

G.S. is the recipient of a grant from the Suntory Institute for Bioorganic Research (Japan). During the course of these studies R.L.Y. was the recipient of a National Health and Medical Research Council of Australia Dora Lush Biomedical Postgraduate Scholarship. This study was supported by grants from the Sir Edward Dunlop Medical Research Foundation and the Austin Hospital Medical Research Foundation.

* Masashi Komeda is currently Professor of the Department of Cardiovascular Surgery, Kyoto University, Shogoin Kawaracho, Sakyo-ku, Kyoto, Japan.

Copyright (C) 2001 by The American Association for Thoracic Surgery

0022-5223/2001 $\$ 35.00+0 \quad \mathbf{1 2 / 1 / 1 1 2 4 6 2}$

doi:10.1067/mtc.2001.112462 cles, leading to the development of left ventricular (LV) dysfunction and heart failure. LV aneurysm resection has been performed many times since the initial procedure was reported by Likoff and Bailey. ${ }^{1}$ The standard linear repair for LV aneurysm excludes the dyskinetic scar and reduces the expanded left ventricle, ${ }^{2}$ thereby restoring cardiac geometry, attenuating wall stresses, and, as a corollary, improving function. Thus far, however, data on hemodynamic improvement of global and regional $\mathrm{LV}$ function after $\mathrm{LV}$ aneurysm repair in human studies have been inconsistent. ${ }^{3-5}$ In animal models, LV aneurysm repair has been largely confined to large animals that have been studied immediately after repair and have failed to demonstrate an improvement in global cardiac function and regional ventricular stress. ${ }^{6}$

Cardiac hypertrophy after MI in the rat is a pathophysiologic response of the heart that contributes to the 
progression toward heart failure and is characterized by the activation of a fetal pattern of cardiac messenger (m)RNA expression. ${ }^{7}$ Neuroendocrine and mechanical stimuli have been shown to induce the expression of pre-pro-atrial natriuretic peptide (ppANP) mRNA and induce fetal isoforms of actin (skeletal $\alpha$-actin [sACT]) and myosin ( $\beta$-myosin heavy chain $[\beta-\mathrm{MHC}]$ ) in neonatal myocytes in vitro. ${ }^{8-10}$ In vivo studies have also confirmed the regional upregulation of these mRNAs in the rat MI model in association with cardiac hypertrophy and within regions undergoing maximal change in diastolic wall tension. ${ }^{7,11}$ However, no studies have examined the influence of LV aneurysm repair after MI in the rat on longer term functional indices and on altered cardiac mRNA distribution.

We report that LV aneurysm repair in rats undergoing infarction improved cardiac performance at 30 weeks and was associated with reduced regional levels of cardiac mRNA encoding ppANP, contractile protein isoforms of adult actin (cardiac $\alpha$-actin [cACT]), adult myosin (myosin light chain-2v [MLC-2v]), and both sACT and $\beta$-MHC, which were detected with in situ hybridization histochemistry.

\section{Methods}

Animals. Wistar rats were obtained from the Biological Research Laboratories, Austin and Repatriation Medical Centre (Heidelberg, Victoria, Australia). All studies were performed in agreement with and according to the Prevention of Cruelty to Animals Act (1986) and the NH\&MRC/CSIRO/ARC* Australian Code of Practice for the Care and Use of Animals for Scientific Purposes (1990) and with the approval of the Austin and Repatriation Medical Centre Animal Ethics Committee.

LV MI. Female Wistar rats weighing 190 to 220 g were subject to ligation of the left anterior descending coronary artery to produce MI, as described by Pfeffer and colleagues $^{12}$ and as modified by us. ${ }^{7}$ Mitral regurgitation is not a feature of the model in our hands (unpublished results), and this finding is supported by other authors. ${ }^{13,14}$ In brief, rats were anesthetized with enflurane (Ethrane), intubated, and ventilated with $1.5 \%$ to $2 \%$ halothane in oxygen. A left thoracotomy was performed at the fourth intercostal space, the pericardium was gently ruptured, and the heart was exteriorized. The left anterior descending coronary artery was ligated 2 to $3 \mathrm{~mm}$ from its origin with a permanent 6-0 monofilament suture. The heart was returned to the chest, the rib space and overlying muscles were closed, and the lungs were reinflated by positive expiratory pressure.

LV aneurysm plication. Four weeks after MI, rats with

*National Health and Medical Research Council/Commonwealth Scientific Industrial Research Organisation/Australian Research Council. electrocardiogram-verified transmural MI (Q-wave depth, >1 $\mathrm{mV}$ ) were anesthetized and underwent a left thoracotomy, during which the heart was carefully dissected free of adhesions to visualize the extent of LV aneurysm. Large LV aneurysms were detected in 27 rats, which were subsequently randomized into 2 groups: a group to be plicated (left ventricular aneurysm repair [LVAR] group, $n=17$ ) and a shamplication group (sham, $\mathrm{n}=10$ ). Group numbers were biased in a ratio of $2: 3$ toward the plication group because of an expected higher mortality in this group. Rats in the sham group had their thoracotomies closed and were allowed to recover. For LVAR rats, the apex of the heart was lifted with fine-tipped forceps to obtain a motionless operative field. A 6-0 monofilament mattress suture was used to place 2 Teflon pledgets $(3 \times 7 \mathrm{~mm})$ on either side of the LV aneurysm, and with the pledgets held together by forceps, the suture was tightly ligated against the mattress reinforcement. The suture width was $5 \mathrm{~mm}$, and it was aligned with prepunched holes in the pledgets. Thereafter, the thoracotomy was closed, and the rats were allowed to recover.

Functional measurements. At 30 weeks after aneurysm repair, all rats were reanesthetized with $1 \%$ halothane in oxygen, the right carotid artery was isolated by means of a cutdown, and a modified polyethylene saline-filled catheter was inserted and retrogradely passed into the left ventricle for continuous pressure monitoring. This modified catheter construct provides a satisfactory signal frequency response to allow accurate measurements of LV pressures. ${ }^{15} \mathrm{LV}$ end-diastolic pressure, LV peak systolic pressure, and rate of change of $\mathrm{LV}$ pressure $( \pm \mathrm{LV} \mathrm{dP/dt})$ were recorded on a MacLab/4E Data Acquisition System (ADInstruments Pty Ltd, Castle Hill, Australia) for subsequent analysis. After functional measurement, the rats were removed from the ventilator and killed by decapitation. The hearts were removed immediately and placed in ice-cold saline solution to arrest in diastole; the lungs, liver, and right kidney were removed, cleared of connective tissue, blotted, and weighed. The heart was subsequently processed and snap frozen according to published methods. ${ }^{7}$ The mean time to saline immersion of the heart after decapitation was 10 seconds, and tissues were snap frozen over liquid nitrogen within 1 minute. An assessment of dry heart weight changes after plication was not possible in the current study because of the requirement for fresh tissue for in situ hybridization histochemistry.

Tissue preparation. Serial transverse sections $(14 \mu \mathrm{m})$ of fresh tissue were cut at 4 levels from the apex (level 1) to base (level 4) of the ventricles (interval, $2.4 \mathrm{~mm}$ ) on a cryostat at $-18^{\circ} \mathrm{C}$. Sections were thaw-mounted onto poly-L-lysine subbed slides, air-dried, and washed in $1 \times$ standard saline citrate (SSC; $1 \times \mathrm{SSC}$ : $0.15 \mathrm{~mol} / \mathrm{L} \mathrm{NaCl}$ and $15 \mathrm{mmol} / \mathrm{L} \mathrm{Na}$ citrate, $\mathrm{pH} 7.0)$ and dehydrated in serial ethanol washes $(70 \%$, $95 \%$, and $100 \%$ ) before storage at $-70^{\circ} \mathrm{C}$.

Oligonucleotide probes. So that the various cardiac mRNA species could be hybridized, DNA oligonucleotide probes (38-45 mers) were prepared complementary to cACT, sACT, MLC-2v, and $\beta$-MHC complementary (c)DNA by Biotech International (Perth, Australia), as 
Table I. Effect of plication on organ weight, scar length, and cardiac function 20 weeks after aneurysm repair

\begin{tabular}{lcc}
\hline & Sham plication & LVAR \\
\hline No. (organ weight, geometry) & 9 & 10 \\
Preoperative body weight $(\mathrm{g})$ & $205 \pm 7$ & $212 \pm 6$ \\
30-week body weight $(\mathrm{g})$ & $309 \pm 9$ & $341 \pm 8$ \\
$\Delta$ Body weight $(\mathrm{g})$ & $104 \pm 11$ & $129 \pm 9^{*}$ \\
Heart weight $(\mathrm{g})$ & $2.36 \pm 0.24$ & $1.98 \pm 0.15$ \\
Heart weight ratio (g/100 g) & $0.76 \pm 0.07$ & $0.58 \pm 0.04^{*}$ \\
Lung weight (g) & $1.75 \pm 0.17$ & $1.70 \pm 0.12$ \\
Lung weight ratio $(\mathrm{g} / 100 \mathrm{~g})$ & $0.57 \pm 0.06$ & $0.50 \pm 0.04$ \\
LV circumference (mm) & $32.0 \pm 1.1$ & $25.9 \pm 1.8 \dagger$ \\
Infarct scar length (mm) & $12.3 \pm 1.0$ & $8.1 \pm 1.3^{*}$ \\
Infarct/LV ratio & $0.38 \pm 0.04$ & $0.31 \pm 0.04$ \\
No. (functional data) & 7 & 8 \\
Heart rate (beats/min) & $279 \pm 27$ & $334 \pm 34$ \\
LVpSP (mm Hg) & $68 \pm 7$ & $87 \pm 9$ \\
LVeDP (mm Hg) & $35 \pm 6$ & $17 \pm 2 \dagger$ \\
LV +dP/dt (mm Hg/s) & $1354 \pm 64$ & $2005 \pm 153 \dagger$ \\
LV -dP/dt (mm Hg/s) & $1099 \pm 35$ & $1477 \pm 150^{*}$ \\
$\tau(\mathrm{ms})$ & $45 \pm 9$ & $47 \pm 5$ \\
\hline
\end{tabular}

Values are represented as mean \pm SEM of the number of rats indicated. Preoperative body weight indicates body weight at infarction. Infarct scar ratio is the ratio of infarct scar length to $L V$ chamber circumference. $L V p S P$, left ventricular peak systolic pressure; $L V e D P$, left venricular end-diastolic pressure.

$* P<.05$ and $\uparrow P<.01$, significant effect of plication (unpaired $t$ test) compared with sham-plicated rat hearts.

described previously. ${ }^{7}$ For ppANP hybridization, a probe complementary to nucleotides 163 to 207 of the ppANP cDNA $^{16}$ (5'-CGC TTC ATC GGT CGT CTC GCT CAG GGC CTG CGG AGG CAT GAC CTC-3’) was prepared. Extra probes were prepared complementary to nucleotides 150 to 188 of rat cACT cDNA $^{17}$ (5'-GGA GCC CCC AAT CCA GAC AGA GTA TTT ACG CTC AGG GGG-3’), 4 to 48 of rat sACT cDNA $^{18}$ (5'-GCC GGC CTC GTC GTA CTC CTG CTT GGT GAT CCA CAT CTG CTG GAA-3'), and 164 to 208 of rat $\beta$-MHC $\mathrm{cDNA}^{19}\left(5^{\prime}\right.$-GCC ATT CTC TGT CTC AGC GGT GAC TTT GCC ACC CTC TCG AGA CAC-3'). These probes were prepared to maximize the specific hybridization signal of the lower abundance mRNAs ${ }^{20}$ and were designed to noncontiguous regions of the cDNA encoded by the original probes and within regions of maximum regional heterogeneity between related mRNAs (cACT, sACT, $\alpha-\mathrm{MHC}$, and $\beta-\mathrm{MHC}$ ). The specificity of all probes for the intended mRNA target was confirmed by means of Basic Local Alignment Search Tool (BLAST) analysis of GenBank, EMBL, DDBJ, and PDB sequence databases. ${ }^{21}$

In situ hybridization histochemistry. Full protocols for in situ hybridization histochemistry, including the preparation of the oligonucleotide probes and densitometric quantification, have been described previously, ${ }^{7}$ except that the current study used single-sided Hyperfilm $\beta$ max film rather than Kodak XOmat film to improve detection sensitivity. In brief, probes were $3^{\prime}$ end labeled with $\left[\alpha^{-}{ }^{35} \mathrm{~S}\right]$ deoxyadenosine triphosphate (1200 $\mathrm{Ci} / \mathrm{mmol}$; Dupont-NEN, Boston, Mass) by using terminal deoxynucleotidyl transferase (AMRAD Pharmacia Biotech, Sydney, Australia) to a specific activity of 1.0 to $2.5 \times 10^{9}$ $\mathrm{dpm} / \mu \mathrm{g}$. Probes $(2 \mathrm{pg} / \mu \mathrm{L}, 65 \mu \mathrm{L}$ per slide) were hybridized to heart sections overnight at $42^{\circ} \mathrm{C}$. Nonspecific hybridization was measured in the presence of a 100 -fold excess of unlabeled probe. Slides were washed in $1 \times \mathrm{SSC}$ for 60 minutes at $55^{\circ} \mathrm{C}$, rinsed at room temperature in $1 \times \mathrm{SSC}$ and $0.1 \times \mathrm{SSC}$, serially dehydrated in ethanol, and air-dried. Sections were then exposed to x-ray film for 1 to 20 days, depending on hybridization signal strength, before development.

Quantitation of cardiac mRNA levels. Cardiac mRNA levels were quantitated by computer-assisted, densitometric image analysis (MicroComputer Imaging Device [MCID]; Imaging Research Inc, St Catharines, Ontario, Canada). Relative optical densities of autoradiographic images were converted to disintegrations per minute per square centimeter by means of interpolation from standard curves generated on individual films from labeled brain paste standards coexposed with tissue sections. The total hybridization signal of $\left[\alpha-{ }^{35} \mathrm{~S}\right]$ deoxyadenosine triphosphate-labeled probes was determined by manually outlining discrete cardiac regions and averaging the total hybridization signal measured on 3 consecutive serial sections from each short-axis level.

Scar length measurement. Transverse sections were stained with Van Geison stain for collagen and were subjected to computer-assisted planimetry (MCID) for determination of LV endocardial circumference and scar length by using planimetry at level 2 , as previously described. ${ }^{7}$ The scar length fraction was expressed as the percentage of endocardial LV circumference replaced by scar tissue.

Statistical analysis. All data are given as means \pm SEM. Effects of plication on rat organ weights, functional indices, and cardiac mRNA levels were analyzed by using the unpaired Students $t$ test (Excel 97-SR2, Microsoft Corporation, Redmond, Wash). 


\section{Results}

Mortality. Mortality of the MI operations was 32\% (20/62), which was consistent with an earlier report from our laboratory. ${ }^{7}$ Of the surviving rats, $25 \%$ (8/42) did not satisfy Q-wave entry criteria on 24-hour electrocardiograms and were excluded from the study. The remaining 34 rats were assigned to the plication study, progressed to the 4-week time point, and appeared healthy. At 4 weeks, 7 of the assigned rats had no visual evidence of expanded LV aneurysm at operation and were excluded from the study. The final 27 rats that underwent MI with LV aneurysm were randomized into 2 groups of similar body weight: the plication group (LVAR) was larger $(n=17)$ than the sham group $(n=10)$ because a higher mortality was expected at operation.

Postoperatively, 2 LVAR rats died within 24 hours of the plication operation (2/17), and 4 (4/15) died within 4 weeks of the plication operation. These deaths were considered to be a consequence of the plication operation. A further LVAR group rat (1/11) and a sham group rat $(1 / 10)$ died at 14 weeks and 11 weeks, respectively, after the plication or sham plication operation. At 30 weeks after aneurysm repair, the remaining 10 LVAR group rats and 9 sham group rats were anesthetized for the purpose of assessing hemodynamic measures and thereafter killed to allow measurement of organ weight and cardiac mRNA changes. Hemodynamic measures, however, were only recorded for 8 LVAR group rats and 7 sham group rats because 2 rats from each study group died during the induction of anesthesia. These latter animals were included in the analyses of organ weight and cardiac mRNA changes and had heart weight ratios that were maximal or near maximal for their respective groups. Corresponding changes in regional cardiac mRNA levels qualitatively reflected these higher values.

Heart and lung weight changes. At 30 weeks after aneurysm repair, rats in the LVAR group had gained more body weight than rats in the nonplicated sham groups $(24 \%, P<.05$, Table I). Heart weight ratio (grams per 100 $\mathrm{g}$ of body weight) was lower in LVAR rats $(31 \%, P<.05$, Table I), whereas lung weight ratio (grams per $100 \mathrm{~g}$ of body weight) was not statistically different in comparison with sham-plicated rats $(P=.29)$.

Intracardiac hemodynamics. Intracardiac hemodynamic results are summarized in Table I. LV peak systolic pressure was higher but not statistically increased in LVAR rats $(28 \%, P=.15)$, whereas $\mathrm{LV}$ end-diastolic pressure was decreased by $51 \%(P<.01)$. Significant increases in peak $\pm \mathrm{dP} / \mathrm{dt}$ were evident in LVAR rats (34\% to $48 \%, P<.05$ ), indicating that $\mathrm{LV}$ plication improved LV function. There was no difference in $\tau$ (time constant of relaxation) between the 2 groups.

Cardiac geometry and scar length. Representative transverse heart sections stained with Van Gieson stain are seen in Fig 1. In both the LVAR and sham groups the LV free wall was involved in transmural infarction, whereas the interventricular septum (IS) remained intact. Anterior papillary muscles in most hearts were atrophied as a result of infarction. In sham-plicated rat hearts the LV chamber was markedly dilated, whereas in plicated rat hearts the heart was more globular and the LV walls appeared thicker after resection and repair of the aneurysm. In plicated rats the length of the infarct scar was significantly reduced $(34 \%, P<.05)$, as was the LV endocardial circumference (19\%, $P<.005$, Table I).

In situ hybridization histochemistry. Levels of PpANP mRNA were detected in ventricular regions at all levels and in all sections examined (Figs 2 and $3)$. In sham-plicated rats ppANP mRNA was detected in the scar-bordering (peri-infarct) regions of the LV and throughout the IS and right ventricle (RV) but was particularly localized to the peri-infarct and IS endocardial regions. A similar ppANP mRNA distribution was evident in LVAR hearts; however, ppANP levels were $58 \%$ to $78 \%$ lower in the LV free wall (levels $1-3, P<.01$, Figs 2 and 3 ), despite persistent ppANP hybridization at either side of the pledgets, and were $43 \%$ to $51 \%$ lower at the midportion of the IS (levels 2 and $3, P<.05$ ).

Levels of $\beta$-MHC mRNA were detected in a homogeneous pattern throughout much of the IS and RV in both sham-plicated and LVAR rats, but higher levels were evident in peri-infarct regions, at the IS epicardium, and in the RV (Figs 4 and 5). Significant differences in $\beta$-MHC mRNA levels were apparent at level 4, where levels in LVAR hearts were $43 \%$ lower in the LV free wall $(P<.05)$, again despite persistent peak $\beta$-MHC hybridization on either side of the pledgets (compared with ppANP). $\beta$-MHC mRNA levels were also lower throughout the IS and RV at this level (43\%$58 \%, P<.05$, Figs 4 and 5).

Levels of sACT mRNA were detected homogeneously throughout the IS and RV of sham-plicated hearts, but like ppANP mRNA, these levels were higher in peri-infarct regions (data not shown). In LVAR hearts, sACT mRNA levels were significantly lower in the LV free wall and IS at level $3(20 \%-28 \%, P<.05$, Fig 6), largely because of regionally reduced levels in the periinfarct region and homogeneously reduced levels throughout the IS. In contrast, cACT mRNA levels were homogeneously and diffusely detected through- 

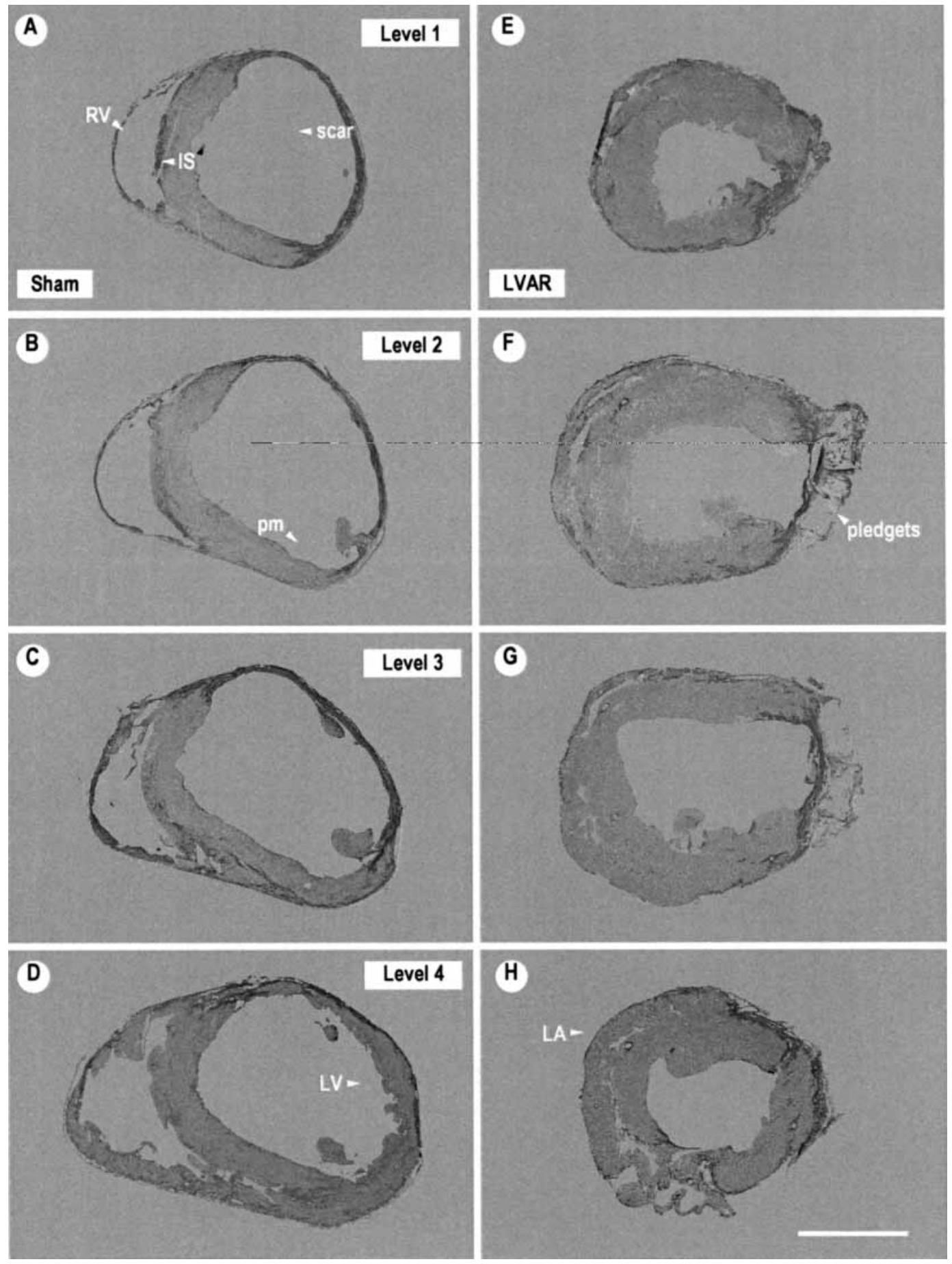

Fig 1. Van Gieson-stained transverse heart sections from sham-plicated (left) and LVAR (right) rat hearts at 30 weeks after aneurysm repair. Resection of aneurysm scar in the left ventricle resulted in a smaller, thicker (less dilated) LV chamber, which was reflected in a significantly lighter heart weight ratio measured in grams per $100 \mathrm{~g}$ of body weight (Table I). This presumably reflects the effects of resection and mass redistribution. Photographs are printed directly from representative slide sections cut from the apex through the base at level 1 (A and E), level 2 (B and F), level 3 (C and G), and level 4 (D and H). LA, Left atrium; pm, papillary muscle (scale bar $=5 \mathrm{~mm}$ ). 

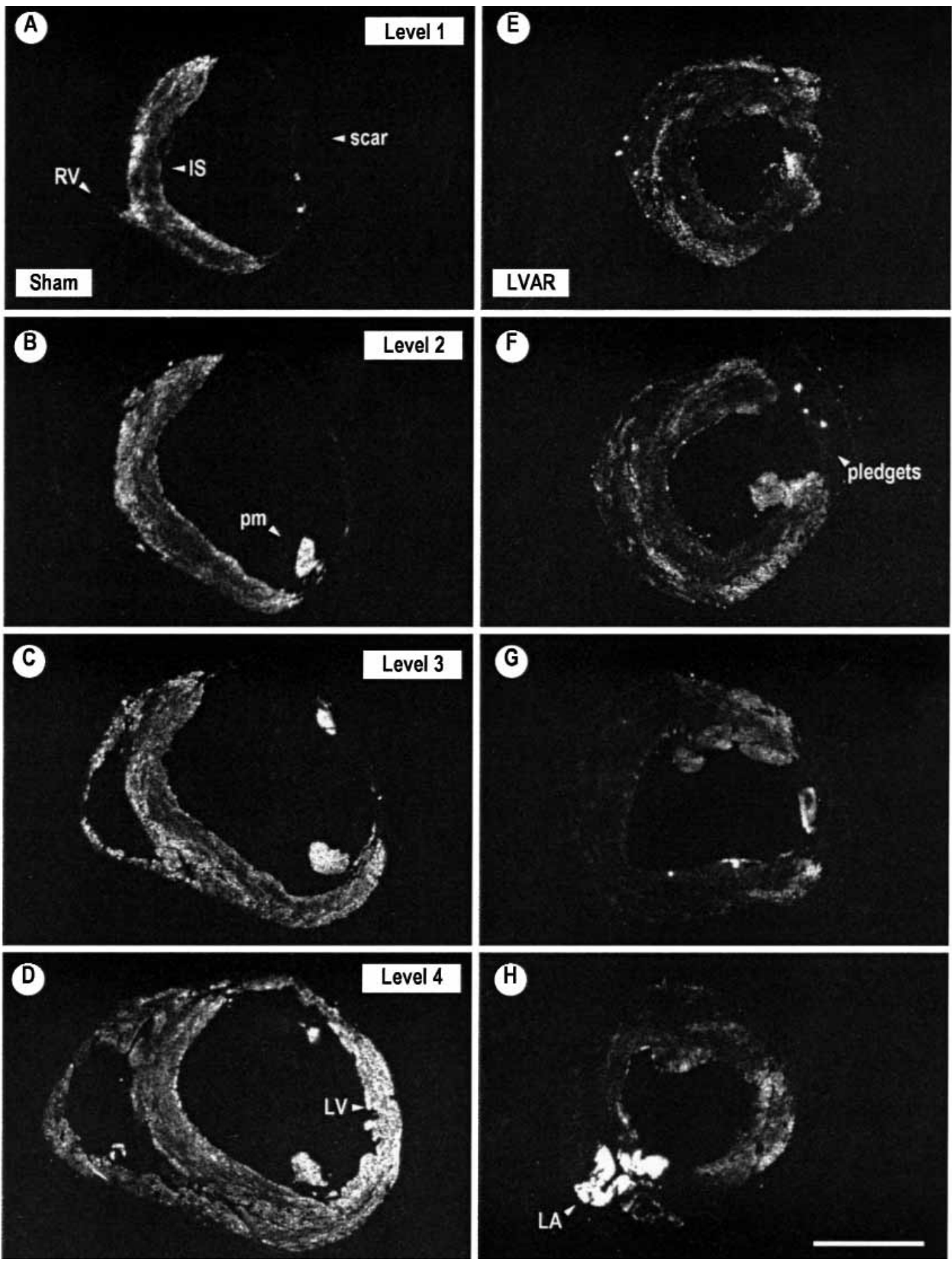

Fig 2. Distribution of ppANP mRNA in sham-plicated (left) and LVAR heart sections (right) at 30 weeks after aneurysm repair. Photographs are printed directly from representative autoradiographs of transverse heart serial sections hybridized with total $\left[{ }^{35} \mathrm{~S}\right]$-labeled oligonucleotide probe complementary to ppANP mRNA, with white areas indicating hybridization. A, Sham: level 1; B, sham: level 2; C, sham: level 3; D, sham: level 4; E, LVAR: level 1; F, LVAR: level 2; G, LVAR: level 3; H, LVAR: level 4. LA, Left atrium; pm, papillary muscle (scale bar = $5 \mathrm{~mm})$. 
LV Free Wall

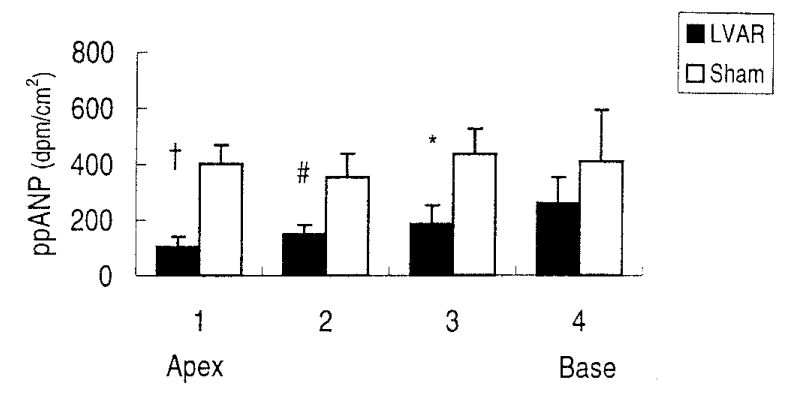

Septum

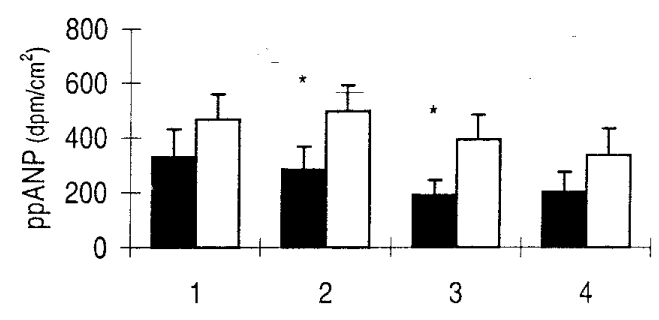

Right Ventricle

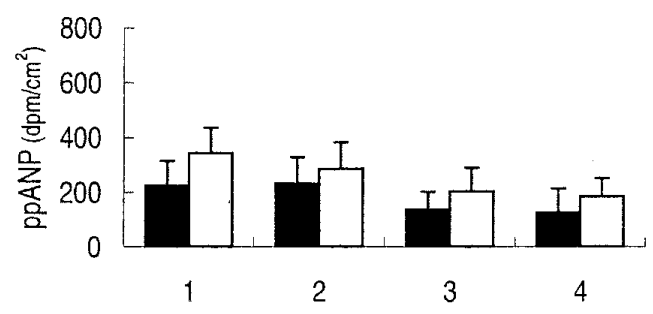

Fig 3. Effects of plication on levels of ppANP mRNA in serial heart sections at 30 weeks after aneurysm repair. Values are represented as means \pm SEM of the number of rats indicated per group in Table I and within regions at the apex (level $1[1]$ ) through the base (level $4[4]$ ). $* P<.05$, $\# P<.01$, and $\dagger P<.005$, significant effect of plication (unpaired $t$ test) compared with sham-plicated rat hearts within the region.

out the ventricles in both sham-plicated and LVAR hearts and were not different between groups (data not shown).

In both sham-plicated and LVAR hearts, MLC-2v mRNA levels were homogeneous and of a moderate to high level throughout the ventricles (Fig 7). In LVAR hearts MLC-2v mRNA levels were markedly reduced in a homogeneous manner at levels 3 and 4 of the LV free wall $(52 \%-56 \%, P<.05)$ and throughout the IS and RV at level $4(51 \%-56 \%, P<.05)$.
In the posterior papillary muscle, ppANP (59\%), $\beta$-MHC (32\%), and sACT (14\%) mRNA levels were all significantly lower in LVAR hearts compared with sham-plicated hearts $(P<.01$, Fig 8$)$.

\section{Discussion}

The present study examined the effect of LV aneurysm repair in infarcted rat hearts on cardiac structure and function and examined the spatiotemporal distribution of cardiac mRNA levels by using in situ hybridization histochemistry in serial short-axis sections. In surviving LVAR rats aneurysm repair by means of plication produced striking improvements in cardiac function, attenuated the increase in heart weight ratio, and reduced regional ppANP mRNA levels, indicating significant functional and molecular benefits of the plication operation. LV aneurysm repair also reduced the regional expression of contractile protein mRNAs ( $\beta$-MHC, sACT, and MLC-2v) at 30 weeks after aneurysm repair.

Cardiac remodeling after transmural MI is associated with cardiac myocyte hypertrophy within the remaining viable myocardium. This process involves an increase in myocardial mass primarily by means of the serial addition of new sarcomeres and fiber elongation without relative wall thickening (eccentric hypertrophy), ${ }^{22}$ resulting in chamber enlargement. At the level of cardiac gene expression, phenotypic conversion from the adult cACT and $\beta$-MHC mRNA isoforms of actin and myosin to the fetal sACT and $\beta$-MHC mRNAs has been reported after neuroendocrine stimulation, mechanical stimulation, or both, of cultured neonatal rat cardiac myocytes. ${ }^{23}$ Complementary findings have also been reported after production of aortic stenosis, ${ }^{24}$ aortocaval fistula, ${ }^{25}$ and MI in rats. ${ }^{7}$ Increased mRNA expression and cellular accumulation of the adult isomyosin MLC- $2 \mathrm{v}$ and re-expression of ventricular ppANP mRNA have also been reported as features of the hypertrophic process. ${ }^{26,27}$ The upregulation of these genes is associated with hemodynamic deterioration and geometric remodeling in the noninfarcted, as well as in infarcted, myocardium.

A large transmural infarction of the left ventricle of the rat leads to a geometric change in the heart from ellipsoidal to cylindrical, and an increase in the radius of curvature at the apex results in a marked elevation of stress at this site. ${ }^{11}$ Excision of a substantive part of the scar and the aneurysmal dilatation leads to a more normal cardiac configuration and increased wall thickness. In accordance with Laplace's law, LV free-wall stress is directly related to chamber dimension and pressure and inversely related to wall thickness. ${ }^{28}$ In the present 

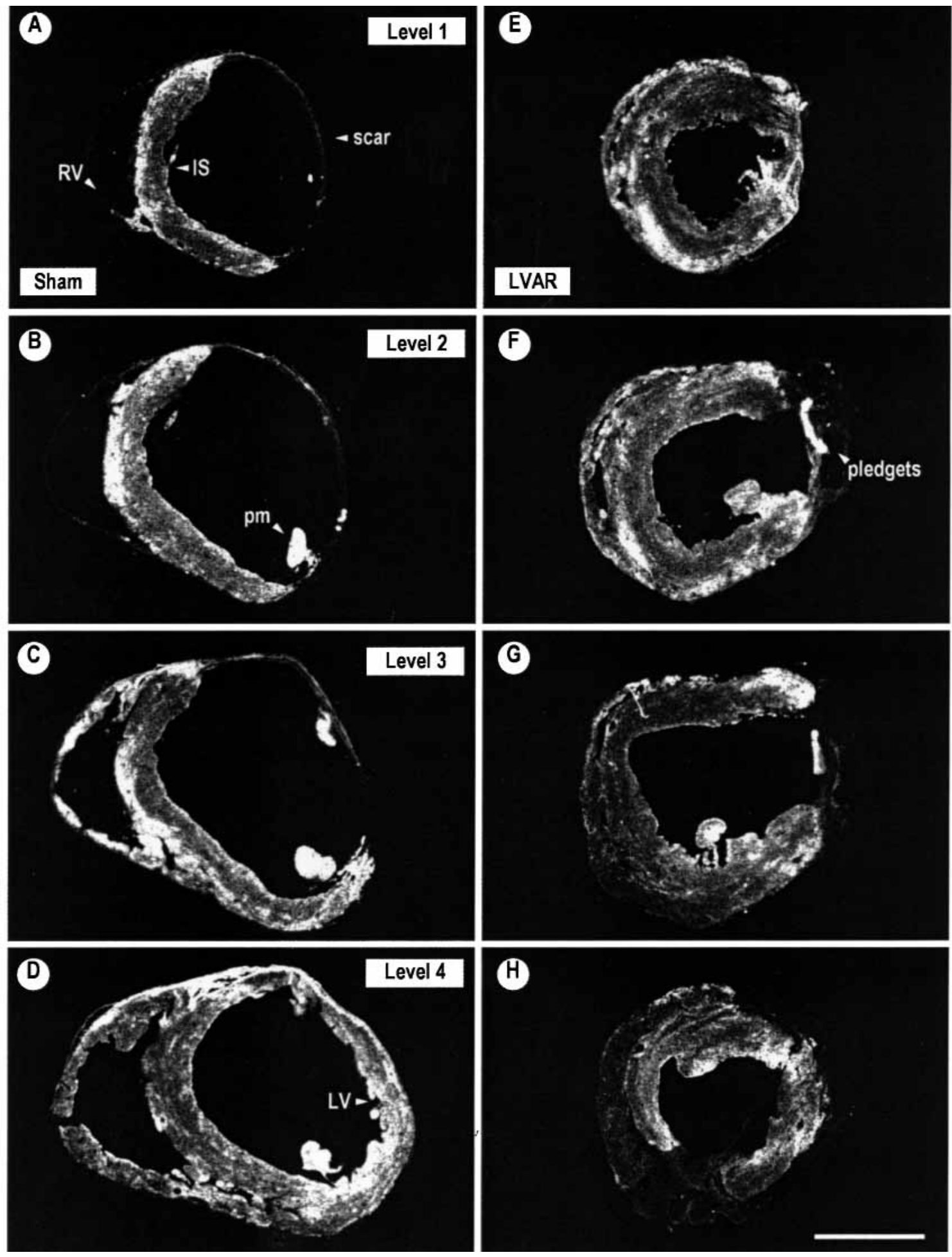

Fig 4. Distribution of $\beta$-MHC mRNA in sham-plicated (left) and LVAR heart sections (right) at 30 weeks after aneurysm repair. Photographs are printed directly from representative autoradiographs of transverse heart serial sections hybridized with total $\left[{ }^{35} \mathrm{~S}\right]$-labeled oligonucleotide probe complementary to $\beta$-MHC mRNA, with white areas indicating hybridization. A, Sham: level 1; B, sham: level 2; C, sham: level 3; D, sham: level 4; E, LVAR: level 1; F, LVAR: level 2; G, LVAR: level 3; H, LVAR: level 4 (scale bar = $5 \mathrm{~mm}$ ). 
LV Free Wall

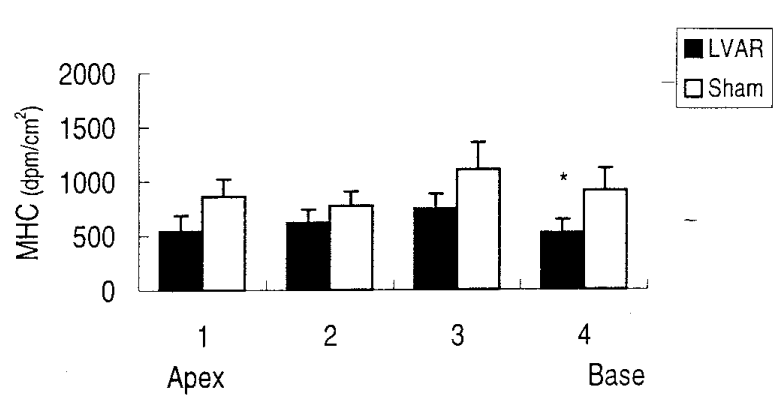

Septum

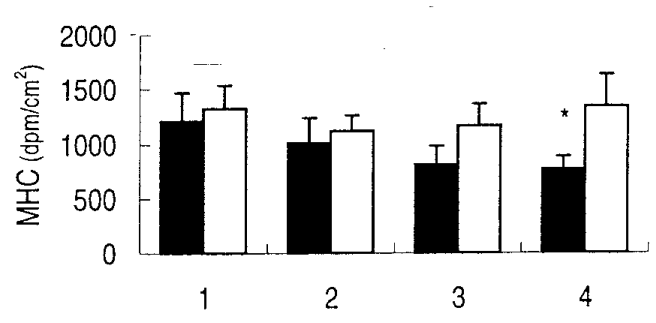

Right Ventricle

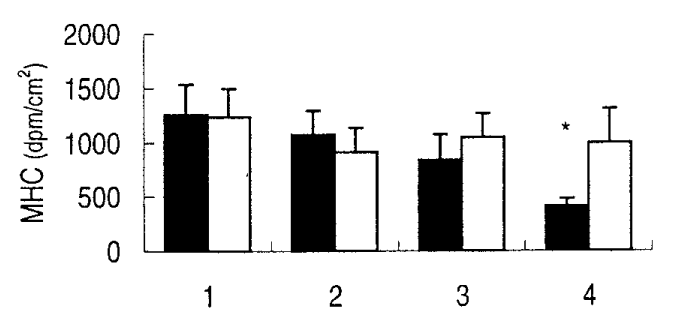

Fig 5. Effects of plication on levels of $\beta$-MHC mRNA in serial heart sections at 30 weeks after aneurysm repair. Values are represented as means \pm SEM of the number of rats indicated per group in Table I and within regions at the apex (level 1 [1]) through the base (level 4 [4]). $* P<.05$, significant effect of plication (unpaired $t$ test) compared with shamplicated rat hearts within the region.

study the reduction of ventricular volume and the elimination of the dyskinetic scar presumably led to reduced ventricular wall stress and thereby improved cardiac performance and reduced heart weight ratio. However, because the in situ hybridization histochemistry protocol did not allow measurements of dry heart weight, we could not establish the degree to which this reduction was caused by reduced edema. Consistent with the conclusion that plication of the infarct scar in the anterolateral apical LV free wall reduces the elevat-

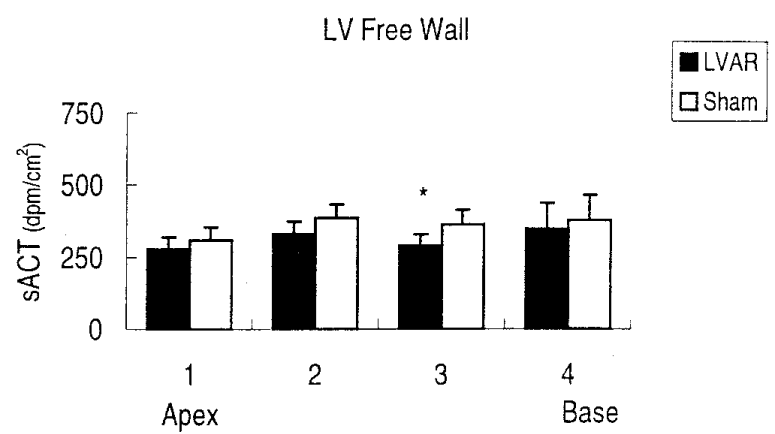

Septum

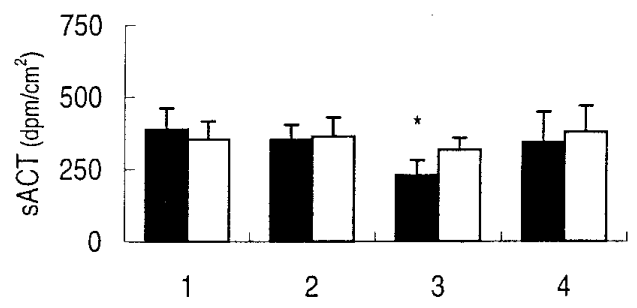

Right Ventricle

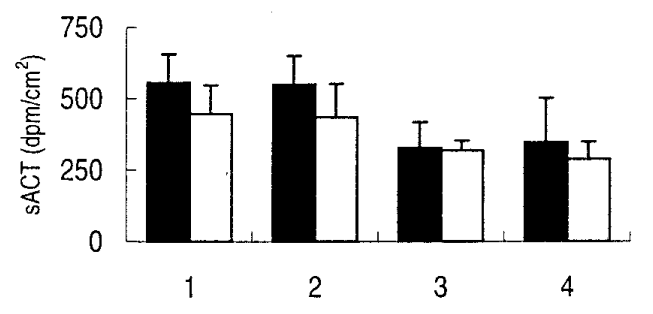

Fig 6. Effects of plication on levels of sACT mRNA in serial heart sections at 30 weeks after aneurysm repair. Values are represented as means \pm SEM of the number of rats indicated per group in Table I and within regions at the apex (level 1 [1]) through the base (level 4 [4]). $* P<.05$, significant effect of plication (unpaired $t$ test) compared with sham-plicated rat hearts within the region.

ed wall stress of surviving myocardium, the level of ppANP mRNA in LVAR hearts was markedly reduced in the apical LV free wall, particularly in the periinfarct zone, regions known to express the highest ppANP mRNA levels after MI. ${ }^{7}$ Wall stress reduction, however, is not the only explanation for these results because the plication operation also had an effect on the expression of cardiac mRNAs at the base (level 4), particularly in noninfarcted infundibular regions, where $\beta$-MHC and MLC-2v mRNA levels were signif- 
LV Free Wall

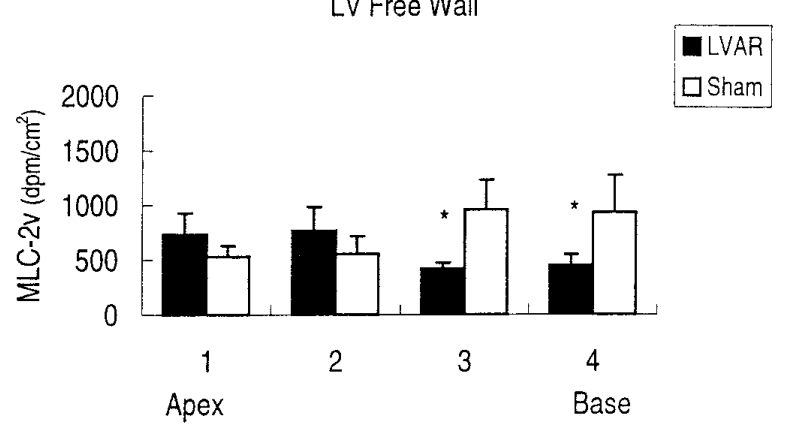

Septum

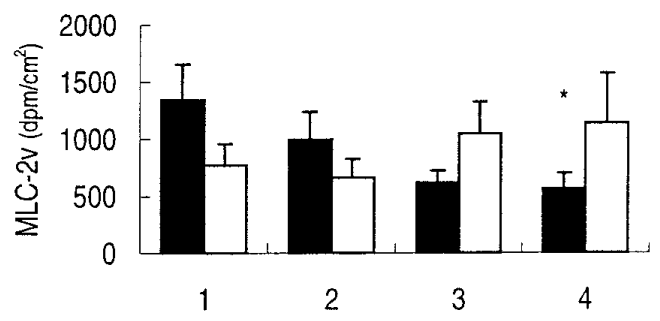

Right Ventricle

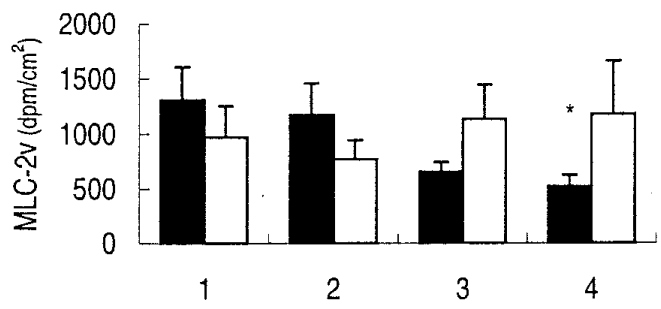

Fig 7. Effects of plication on levels of MLC-2v mRNA in serial heart sections at 30 weeks after aneurysm repair. Values are represented as means \pm SEM of the number of rats indicated per group in Table I and within regions at the apex (level $1[1]$ ) through the base (level $4[4]$ ). ${ }^{*} P<.05$, significant effect of plication (unpaired $t$ test) compared with shamplicated rat hearts within the region.

icantly reduced in LVAR hearts. It is less likely that plication would affect wall tension in this region, implying that the altered mRNA levels are also likely to result from an effect of plication on hemodynamic preload. Not all functional indices improved with plication, however. Although peak systolic pressures were higher in plicated rats, they did not achieve statistical significance. Furthermore, $\tau$ did not decrease, indicating that the early active phase of diastole was not improved in the plication group.

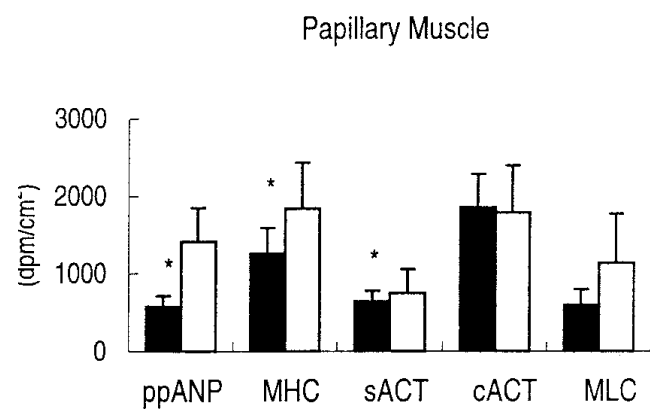

Fig 8. Effects of plication on levels of ppANP, $\beta$-MHC, and sACT mRNA in posterior papillary muscles at 30 weeks after aneurysm repair. Values are represented as means \pm SEM of the number of rats indicated per group in Table I and within regions at the apex (level 1 [1]) through the base (level 4 [4]). $* P<.05, \# P<.01$, and $\dagger P<.005$, significant effect of plication (unpaired $t$ test) compared with sham-plicated rat hearts within the region.

In infarcted rat hearts the LV free wall is composed of a large infarct scar, a peri-infarct zone, and a noninfarcted region, with distinct cardiac mRNA levels within these regions of the LV free wall. Morphometric studies have shown that the processes that cause hypertrophy of the ventricular free wall demonstrate qualitatively similar changes in the papillary muscles. ${ }^{29}$ Because of the segmental nature of hypertrophic change of the ischemic LV, noninfarcted papillary muscle can be considered representative of the remainder of the myocardium. ${ }^{30}$ Our investigation showed that although the expression of cardiac mRNA levels in papillary muscle after infarction was higher than that found in other areas of the heart, levels of ppANP, $\beta$ MHC, and sACT mRNA were again significantly reduced in LVAR hearts.

In the present study RV levels of $\beta$-MHC and MLC$2 \mathrm{v}$ mRNA at the base (level 4) were attenuated in the plication group. Messenger RNA levels of ppANP, sACT, and $\beta$-MHC are known to increase in the RV after MI in rats, ${ }^{7}$ and ppANP and sACT mRNA levels increase in the RV of rats with RV hypertrophy produced by pulmonary arterial banding. ${ }^{31}$ Hemodynamic overload of the left ventricle may influence the RV through the pulmonary circulation or the IS; however, it is unclear whether direct mechanical stress itself or neurohormonal factors evoked by stress stimulated these mRNA levels in the RV.

Despite the apparent benefits of LV aneurysm plication in this study, we found that the plication procedure had some limitations. First, the infarct scar in this model was large $(44.5 \% \pm 2.7 \%$ of the LV surface 
area), ${ }^{7}$ making it difficult to consistently plicate the entire scar area. As a consequence, the nonplicated scar may have re-expanded during the 30 -week period after plication, allowing some LVAR hearts to became enlarged and resulting in individual variation in benefit. Second, there was a persistence of increased mRNA levels at either side of the pledgets in the peri-infarct region, suggesting that this region of the LV free wall was still subject to increased stress in LVAR rats. Finally, the mortality of the LVAR group in the present study was higher than that of the sham group; 5 LVAR rats died after the plication, 4 of them within 4 weeks of the operation. Our recent experience, however, suggests that this initial mortality was due to technical failures because we now have an extremely low mortality from plication operations, with no deaths reported in our latest series of 18 LVAR rats (unpublished observations). Finally, there are differences between rat and human models in that septal necrosis is almost always present with left anterior descending occlusion in human patients, whereas it is only seen in large infarcts $(>45 \%)$ in the rat. ${ }^{15}$

In conclusion, the plication of LV aneurysm in a rat model of MI improved cardiac function and reduced the upregulation of ppANP mRNA, $\beta$-MHC mRNA, sACT mRNA, and MLC-2v mRNA in the long term. Further studies are required to establish criteria for optimum reduction of ventricular volume.

We thank Mr Terry Cass and Simon Eades (Department of Anatomical Pathology, Austin and Repatriation Medical Centre) for assistance with staining of heart sections.

Received for publication Feb 7, 2000; revisions received Oct 4, 2000; accepted for publication Oct 20, 2000.

Address for reprints: Richard L. Young, PhD, Department of Clinical Pharmacology and Therapeutics, Austin and Repatriation Medical Centre, Heidelberg, Victoria 3084, Australia (E-mail: richardy@ ariel.ucs.unimelb.edu.au).

\section{REFERENCES}

1. Likoff W, Bailey CP. Excision of myocardial aneurysm, report of a successful case. JAMA 1955;158:915.

2. Olearchyk AS, Lemole GM, Spagna PM. Left ventricular aneurysm: ten years' experience in surgical treatment of 244 cases-improved clinical status, hemodynamics, and long-term longevity. J Thorac Cardiovasc Surg 1984;88:544-53.

3. Mickleborough LL, Maruyama H, Liu P, Mohamed S. Results of left ventricular aneurysmectomy with a tailored scar excision and primary closure technique. J Thorac Cardiovasc Surg 1994;107:690-8.

4. Komeda M, David TE, Malik A, Ivanov J, Sun Z. Operative risks and long-term results of operation for left ventricular aneurysm. Ann Thorac Surg 1992;53:22-9.
5. Nicolosi AC, Spotnitz HM. Quantitative analysis of regional systolic function with left ventricular aneurysm. Circulation 1988;78:856-62.

6. Savage EB, Downing SW, Ratcliffe MB, Fallert M, Gupta KB, Tyson GS, et al. Repair of left ventricular aneurysm: changes in ventricular mechanics, hemodynamics, and oxygen consumption. J Thorac Cardiovasc Surg 1992;104:752-62.

7. Young RL, Gundlach AL, Louis WJ. Altered cardiac hormone and contractile protein messenger RNA levels following left ventricular myocardial infarction in the rat: an in situ hybridization histochemical study. Cardiovasc Res 1998;37:187-201.

8. Gardner DG, Wirtz H, Dobbs LG. Stretch-dependent regulation of atrial peptide synthesis and secretion in cultured atrial cardiocytes. Am J Physiol 1992;263:E239-44.

9. Komuro I, Yazaki Y. Control of cardiac gene expression by mechanical stress. Ann Rev Physiol 1993;55:55-75.

10. Shalitin N, Friedman M, Schlesinger H, Barhum Y, Levy MJ, Schaper W, et al. The effect of angiotensin II on myosin heavy chain expression in cultured myocardial cells. In Vitro Cell Dev Biol Anim 1996;32:573-8.

11. Capasso JM, Li P, Zhang X, Anversa P. Heterogeneity of ventricular remodeling after acute myocardial infarction in rats. Am J Physiol 1992;262:H486-95.

12. Pfeffer MA, Pfeffer JM, Fishbein MC, Fletcher PJ, Spadaro J, Kloner RA, et al. Myocardial infarct size and ventricular function in rats. Circ Res 1979;44:503-12.

13. Litwin SE, Katz SE, Morgan JP, Douglas PS. Serial echocardiographic assessment of left ventricular geometry and function after large myocardial infarction in the rat. Circulation 1994;89:345-54.

14. Yoshiyama M, Takeuchi K, Omura T, Kim S, Yamagishi H, Toda $\mathrm{I}$, et al. Effects of candesartan and cilazapril on rats with myocardial infarction assessed by echocardiography. Hypertension 1999;33:961-8.

15. Young RL. Cardiac hypertrophy and failure following myocardial infarction in the rat: functional, molecular and receptor studies [thesis]. Melbourne (Australia): University of Melbourne; 1999.

16. Maki M, Takayanagi R, Misono KS, Pandey KN, Tibbetts C, Inagami $\mathrm{T}$. Structure of rat atrial natriuretic factor precursor deduced from cDNA sequence. Nature 1984;309:722-4.

17. Mayer Y, Czosnek H, Zeelon PE, Yaffe D, Nudel U. Expression of the genes coding for the skeletal muscle and cardiac actions in the heart. Nucleic Acids Res 1984;12:1087-100.

18. Shani M, Nudel U, Zevin-Sonkin D, Zakut R, Givol D, Katcoff D, et al. Skeletal muscle actin mRNA. Characterization of the 3' untranslated region. Nucleic Acids Res 1981;9:579-89.

19. Kraft R, Bravo-Zehnder M, Taylor DA, Leinwand LA. Complete nucleotide sequence of full length cDNA for rat beta cardiac myosin heavy chain. Nucleic Acids Res 1989;17:752930.

20. Wisden W, Morris BJ. In situ hybridization with synthetic oligonucleotide probes. In: Wisden W, Morris BJ, editors. In situ hybridization histochemistry protocols for the brain. London: Academic Press; 1994. p. 9-34.

21. Altschul SF, Gish W, Miller W, Myers EW, Lipman DJ. Basic local alignment search tool. J Mol Biol 1990;215:403-10.

22. Grossman W. Cardiac hypertrophy: Useful adaptation or pathologic process? Am J Med 1980;69:576-84. 
23. Bishopric NH, Simpson PC, Ordahl CP. Induction of the skeletal alpha-actin gene in alpha 1-adrenoceptor-mediated hypertrophy of rat cardiac myocytes. J Clin Invest 1987;80:1194-9.

24. Schiaffino S, Samuel JL, Sassoon D, Lompre AM, Garner I, Marotte F, et al. Nonsynchronous accumulation of alpha-skeletal actin and beta-myosin heavy chain mRNAs during early stages of pressure-overload-induced cardiac hypertrophy demonstrated by in situ hybridization. Circ Res 1989;64:937-48.

25. Mercadier JJ, Lompre AM, Wisnewsky C, Samuel JL, Bercovici $\mathrm{J}$, Swynghedauw B, et al. Myosin isoenzyme changes in several models of rat cardiac hypertrophy. Circ Res 1981;49:525-32.

26. Drexler H, Hanze J, Finckh M, Lu W, Just H, Lang RE. Atrial natriuretic peptide in a rat model of cardiac failure: atrial and ventricular mRNA, atrial content, plasma levels, and effect of volume loading. Circulation 1989;79:620-33.

27. Knowlton KU, Baracchini E, Ross RS, Harris AN, Henderson SA, Evans SM, et al. Co-regulation of the atrial natriuretic factor and cardiac myosin light chain-2 genes during alpha-adrenergic stimulation of neonatal rat ventricular cells: identification of cis sequences within an embryonic and a constitutive contractile protein gene which mediate inducible expression. J Biol Chem 1991;266:7759-68.

28. Borow KM, Lang RM, Neumann A, Carroll JD, Rajfer SI. Physiologic mechanisms governing hemodynamic responses to positive inotropic therapy in patients with dilated cardiomyopathy. Circulation 1988;77:625-37.

29. Wakafuji S, Shirai T, Okada R. Histopathological study of the papillary muscles and apex cordis of the hypertrophied left ventricle. Jpn Circ J 1987;51:527-34.

30. Warner AL, Bellah KL, Raya TE, Roeske WR, Goldman S. Effects of beta-adrenergic blockade on papillary muscle function and the beta-adrenergic receptor system in noninfarcted myocardium in compensated ischemic left ventricular dysfunction. Circulation 1992;86:1584-95.

31. Adachi S, Ito H, Ohta Y, Tanaka M, Ishiyama S, Nagata M, et al. Distribution of mRNAs for natriuretic peptides in RV hypertrophy after pulmonary arterial banding. Am J Physiol 1995;268:H162-9. 